\title{
Freight Transport Using Short Sea Shipping
}

\author{
Xavier Ametller \\ SENER Ingenieríay Sistemas Ports, Water \& Environment Section, C/Creu Casas i Sicart 86-88 - Parc de l'Alba 08290 Cerdanyola \\ del Vallès Barcelona
}

\begin{abstract}
The increasing imbalance between road and maritime transport has led to saturation of the terrestrial infrastructures. For this reason, the development and analysis of an intermodal freight transport which is safe, reliable and sustainable is the first step to a more balanced growth of other transport options. In this sense, SSS (Short Sea Shipping) rises like a real and efficient alternative to the land road-based transport as well as integrated to a multimodal system door to door for the freight distribution. This paper aims to evaluate and identify all those parameters required to determine the characteristics of a SSS service under a theoretical approach. The increasing growth of the transport market demands to the maritime transport an adaptation effort to the redistribution space processes of production centers and consumption and, as a result of it, of the logistic flows and transport. For this reason, a specific methodology has been developed to model all those phases integrated in the logistic chain of SSS. The final purpose is to determine costs and time of each one of them, for its later implementation in a heuristic algorithm of routing analysis. The main driving factors that determine under which conditions the SSS represents an effective and a feasible solution to road freight are also identified. Information regarding European Union programs to promote the SSS is also presented for a better understanding of the ways of funding sustainable freight transport projects. This investigation states an initial basis for evaluating the competitiveness of SSS concepts, and shows where market and environmental circumstances could be handled in order to enhance the competitiveness of SSS.
\end{abstract}

Key words: Short Sea Shipping, Barcelona, container, port.

\section{A Theoretical Approach to the Short Sea Shipping}

\subsection{Building the SSS Model}

A many-to-many approach has been developed to build a cost-time SSS model. The door-to-door transport model includes three main parts:

Road freight transport. Includes all road based and land operations which consume time and distance.

Port terminal operations (either origin or destination). This interface includes all port terminal operations that allow changing the land transport mode to maritime. These activities only consume time.

Sea transport. Includes the movement of cargo by sea which consumes time and distance.

For any origin-destination pair, the SSS model allows that the freight transport can be a pure road

Corresponding author: Xavier Ametller, MSc, research fields: ports \& logistics, port infrastructures, transport planning. Email: xavier.ametller@gmail. chain from many origins to many destinations or a SSS typical chain that includes the sea link. For the sake of clarity, the model only allows one sea link between any origin and any destination. Please refer to Fig. 1 for a concept scheme of those possibilities.

The model is fed with Cobb-Douglas equations which have been obtained through the analyses of thirty-one (31) RoRo/RoPax vessels and marketland and port freight transport costs of the south Mediterranean region. Stock costs have not been included in the table.

$$
\begin{gathered}
C_{t}\left(d_{i j}\right)=0.966 \cdot d_{i j} \\
T_{t}\left(d_{i j}\right)=0.0265 \cdot d_{i j} \\
C_{o p}(S)=235.064 \cdot S^{0.441} \\
T_{o p}(S)=0.037 \cdot S^{0.483} \\
C_{m}(S)=\sum_{i=1}^{5} f_{i}(S) \\
f_{1}(S)=0.248 \cdot S^{0.937} \\
f_{2}(S)=0.009 \cdot S^{0.937} \\
f_{3}(S)=160.061 \cdot S^{0.216} \\
f_{4}(S)=0.022 \cdot S^{0.673}
\end{gathered}
$$


Table 1 SSS model equations. Source: Own elaboration.

\begin{tabular}{|c|c|c|}
\hline SSS & Item & \\
\hline \multirow{2}{*}{ Road transport } & Land costs $(€)$ & \\
\hline & Land time (h) & \\
\hline \multirow{2}{*}{ Port operations } & Port operation costs $(€)$ & \\
\hline & Terminal time (h) & \\
\hline \multirow{7}{*}{ Sea transport } & Sea costs & \\
\hline & Capital vessel costs (€/day) & \\
\hline & Operation \& Maintenance costs( $€ / \mathrm{d}$ & \\
\hline & Crew costs ( $€ /$ day) & \\
\hline & Fuel costs (€/day) & \\
\hline & Port taxes (€/stop) & \\
\hline & Sea time (h) & \\
\hline \multicolumn{3}{|c|}{$f_{5}(S)=0.021 \cdot S+85.61 \cdot S^{0.441}+1.495 \cdot S^{0.544}+$} \\
\hline \multirow[t]{2}{*}{$79.931 \cdot S^{0.6}$} & 99 & $(10)$ \\
\hline & $T_{m}\left(S, d_{m}\right)=\frac{d_{m}}{2.877 S^{0.201}}$ & (11) \\
\hline
\end{tabular}

where,

$$
\begin{aligned}
& d_{i j}=\text { land distance }(\mathrm{km}) ; \\
& d_{m}=\text { sea distance (nautical miles, nmi); } \\
& S \text { = gross tonnage of the vessel (GT). }
\end{aligned}
$$

It is important to highlight that the gross tonnage of the vessel $(S)$ has been selected as the variable to write the equations. The gross tonnage can be written as a function of the total number of platforms (or demand) that the vessel can transport:

$$
S(n)=3.532 n^{1.699}
$$

where,

$n$ =maximum capacity of the vessel in terms of the number of platforms.

It should be noted that costs are in euro (2005 base year). Local differences have a great impact on the equations presented in Table 1 and equations should be developed accordingly. For further information regarding modeling details please refer to AMETLLER, XAVIER i SAURÍ, SERGI (2007).

\subsection{Defining a Transport Problem-a Simple Approach}

For a certain group of land origins and destinations related to a fixed sea link (same port of origin and port of destination) the logistic problem to solve is to find the routes that minimize the overall cost of freight transport subject to certain restrictions. Hence, let the origins be $\quad i \in N=\{1,2,3 \ldots, n\} \quad$, destinations $j \in M=\{1,2,3 \ldots, m\}$, and the platform demand $p_{i j}$ (or whatever unit of transport) that should be transported from $i$ to $j$ by road or using SSS. The following expressions will determine the function to be minimized:

$$
\begin{aligned}
& X_{i j}= \begin{cases}1 & \text { if the platform (or travel demand) } p_{i j} \text { is } \\
0 & \text { from } i \text { to } j \text { by road }\end{cases} \\
& Y_{i j}=\left\{\begin{array}{cc}
1 & \text { if the platform (or travel demand) } \\
0 & p_{i j} \text { uses a port } \\
\text { on the contrary }
\end{array}\right. \\
& W_{i h}=\text { number of trucks ( } 1 \text { platform per truck) from }
\end{aligned}
$$

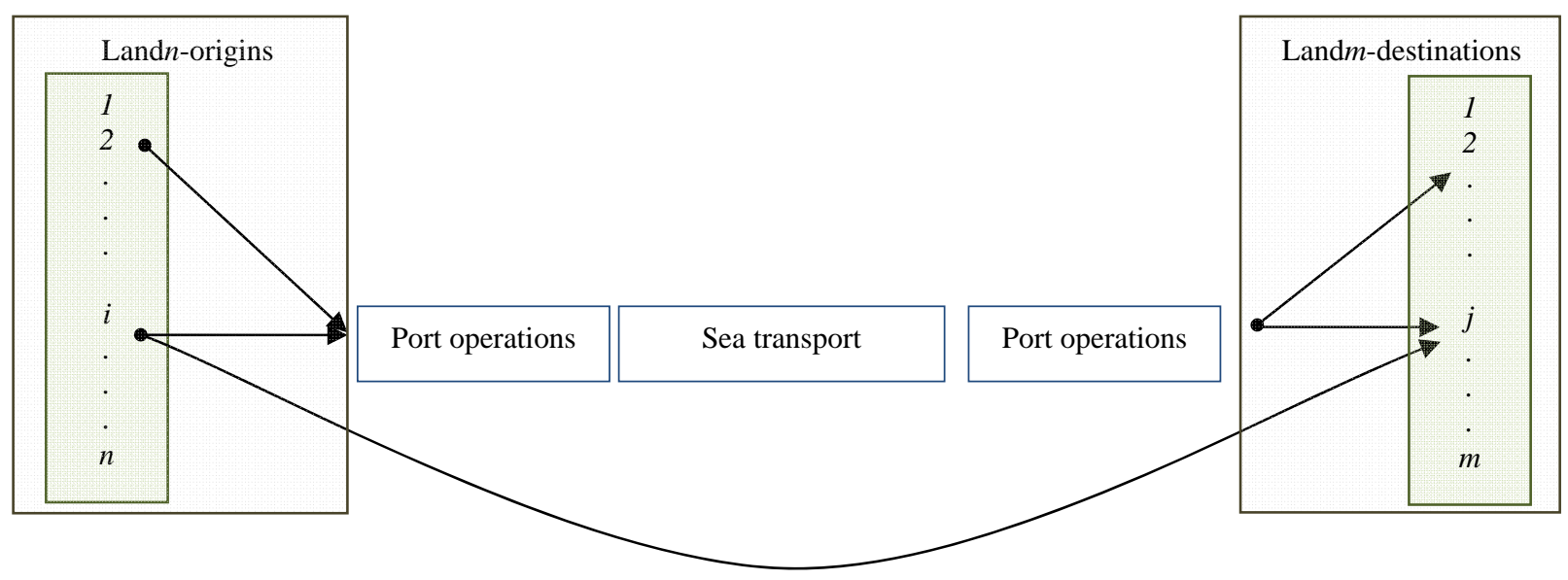

Fig. 1 Many-to-many SSS model. Source: Own elaboration. 
$W_{i j}=$ number of trucks that make a pure road transport;

$W_{h}=$ vessel capacity (in terms of platforms).

Additionally,

For each origin-destination pair there will be only one transport choice.

$$
\begin{array}{cc}
X_{i j}+Y_{i j}=1 & i=1,2,3, \ldots, n \\
& j=1,2,3, \ldots, m \\
X_{i j}, Y_{i j} \in\{0,1\} & i=1,2,3, \ldots, n \\
& j=1,2,3, \ldots, m
\end{array}
$$

The total number of trucks at origin or destination (or equivalently the total number of platforms at the port of origin or destination) will be equal or less to the overall capacity of the vessels at the port of origin.

$$
\begin{aligned}
& \sum_{i=1}^{n} W_{i h} \leq W_{h}(S) \quad i=1,2,3, \ldots, n \\
& \sum_{j=1}^{m} W_{h j} \leq W_{h}(S) \quad j=1,2,3, \ldots, m
\end{aligned}
$$

To obtain $W_{h}$, Eq. 12 can be rewritten as:

$$
n(S)=1.894 S^{0.441}
$$

The following terms are related to cost and time estimations and are also used. Please refer to Eqs.(1)-(19):

$d_{i j}=$ road distance between the origin $i$ and the destination $j(\mathrm{~km})$;

$d_{i h}=$ road distance between the land origin $i$ to the port of origin $(\mathrm{km})$;

$d_{h j}=$ road distance between the port of destination to the land destination $j \quad(\mathrm{~km})$;

$d_{m}=$ sea distance from the port of origin and the port of destination (nautical miles, nmi);

$C_{t}=$ land unit cost $(€ / \mathrm{h})$;

$C_{o p}=$ port operations unit cost (per platform, $€ / \mathrm{p}$ );

$C_{m}=$ sea unit costs (per platform, $€ / p$ );

$r=$ occupation vessel factor (ratio between the existing cargo and the maximum cargo of the vessel);

$\delta=$ profit of the SSS services (\%);

$t_{i j}=$ land time duration (by truck) using pure land transport (h) from the origin $i$ to destination $j$;

$t_{i h}=$ land time duration between the land origin $i$ to the port of origin $(h)$;

$t_{h j}=$ land time duration between the port of destination and the land destination $j(h)$;

$T_{o p}=$ port operation time $(h)$;

$T_{m}=$ sea time duration $(h)$.

The cost logistic equation to be minimized is the following:

$$
\begin{gathered}
\sum_{i=1}^{n} \sum_{j=1}^{m}\left(C_{t}\left(d_{i j}\right)\right) W_{i j} X_{i j}+\sum_{i=1}^{n}\left(C_{t}\left(d_{i h}\right)\right) W_{i h}+ \\
\sum_{j=1}^{m}\left(C_{t}\left(d_{h j}\right)\right) W_{h j}+\sum_{i=1}^{n}\left(C_{o p}\left(W_{i h}\right)\right)+ \\
\sum_{j=1}^{m}\left(C_{o p}\left(W_{h j}\right)\right)+C_{m}\left(S, d_{m}, r, \delta\right) W_{h}
\end{gathered}
$$

Please note that the demand distribution (in terms of platform demand $p_{i j}$ between and origin and a destination given a total freight demand $P$ ) can be estimated by the widely used gravitational model based on the total population.

$$
p_{i j}=\Omega_{i j} \cdot P \quad \begin{aligned}
& i=1,2,3, \ldots, n \\
& j=1,2,3, \ldots, m
\end{aligned}
$$

With,

$p_{i j}=$ platforms with origin $i$ and destination $j$;

$P=$ total freight demand between the origins $i$ and destinations $j$;

$$
\begin{aligned}
& \Omega_{i j}=\text { Gravitational weight defined by: } \\
& \Omega_{i j}=\frac{p_{i}}{\sum_{i=1}^{n} p_{i}} \cdot \frac{p_{j}}{\sum_{j=1}^{m} p_{j} \quad} \quad \begin{array}{r}
j=1,2,3, \ldots, n \\
j=1,2,3, \ldots, m
\end{array} \\
& p_{i}=\text { population of the origin } i ; \\
& p_{j}=\text { population of the destination } j .
\end{aligned}
$$

\subsection{Solving a Transport Problem—a Simple Approach}

Eq. 20 contains one or more unknowns, which are free variables for which values are sought that cause the minimum cost condition to be fulfilled. To be precise, what is sought are often not necessarily actual values, but, more in general, mathematical expressions. Additional expressions are given, in a heuristic form, to assess the logistic problems which are defined as steps: 
Step 1: The algorithm starts by defining an initial occupation factor $r_{0}$ (ratio between the existing cargo and the maximum cargo of the vessel), which allows to define the cost per platform when using the SSS multimodal chain.

Step 2: The algorithm compares the cost of a transporting one platform from $i$ to $j$ by road or SSS as follows:

$$
\text { if } C_{i j, S S S} \leq C_{i j, R O A D} \Rightarrow X_{i j}=0 \quad \begin{aligned}
& i=1,2,3, \ldots, n \\
& j=1,2,3, \ldots, m \\
& r=r_{0}
\end{aligned}
$$

Step 3: The algorithm checks the Eqs. (17)-(18) to make sure that the capacity of the vessels is not overpassed. The vessel is loaded starting with the biggest order $p_{i j}$ simulating the fact that companies with high export volumes have preferred contracts with shipping companies. After this loading criteria, there will be a first approximation of the number of trucks, from an origin $i$ that are allowed to go the port of origin. Eq. 22 describes the vessel loading criteria:

$$
\begin{aligned}
& \hat{W}_{\text {ih }}=\max \left\{W_{i h}\right\} \\
& \text { if } \sum_{i=1}^{n} \sum_{j=1}^{m} \hat{W}_{i h} Y_{i j}<W_{h} \Rightarrow \quad \begin{array}{c}
i=1,2,3, \ldots, n \\
j=1,2,3, \ldots, m
\end{array} \\
& W_{i h}=\left\{W_{1 h}, \ldots, W_{n h}\right\}-\hat{W}_{i h}
\end{aligned}
$$

Where,

$Y_{i j}= \begin{cases}1 & \text { if the platform (or travel demand) } \mathrm{p}_{\mathrm{ij}} \text { uses } \\ 0 & \text { on the contrary }\end{cases}$

$W_{i h}=$ Number of trucks from the land origin $i$ to the port of origin.

Step 4: Following the steps above, an initial solution is stored in the matrix $X_{i j}$ which meets optimized cost criteria. At this point, the algorithm updates the value of the occupation factor $r$ which was defined as a default number in Step 1 with its actual value until an error tolerance (set at a value of $r-r_{0} \leq 1 \%$ ) is reached:

$$
r=\frac{\sum_{i=1}^{n} W_{i h} Y_{i j}}{W_{h}} \quad \begin{aligned}
& i=1,2,3, \ldots, n \\
& j=1,2,3, \ldots, m
\end{aligned}
$$

Following the step defined above the solution matrix $X_{i j}$ is updated.

Step 5: Once the occupation factor $r$ is stable, the algorithm evaluates and compares the time duration of each mode (road and SSS) for each origin-destination pair. A new parameter in the algorithm $\Delta t$ is included, which is the maximum time percentage that the SSS can be slower compared to the road to retain the cargo. For example, if $\Delta t=25 \%$ and following economic criteria the freight should be moved by SSS ( $X_{i j}=0$ ), and $T_{i j, S S S}=49 \mathrm{~h}$ and $T_{i j, \text { ROAD }}=40 \mathrm{~h}$, the algorithm evaluates the condition $T_{i j, \text { SSS }}<(1+\Delta t) T_{i j, \text { ROAD }}$, fulfilled in this case as $49 h \leq 40 h \cdot(1+25 \%)=50 h$. The purpose of this constraint is to provide a limit by which the time flexibility is considered regardless of strictly cost criteria.

$$
\begin{aligned}
& \text { if } X_{i j}=0 \wedge T_{i j, \text { SSS }}<\quad i=1,2,3, \ldots, n \\
& (1+\Delta t) T_{i j, R O A D} \Rightarrow X_{i j}=0 \quad j=1,2,3, \ldots, m
\end{aligned}
$$

This final step makes necessary to update the solution $X_{i j}$ and repeat the sequence until the occupation factor is stable. This model was successfully tested with real data of South Mediterranean SSS routes.

Kindly refer to AMETLLER, XAVIER i SAURÍ, SERGI (2007) for a complete description of the model and a Microsoft Visual Basic (C) code implemented in an Excel @ spreadsheet.

\subsection{Key Factors in the SSS}

The model is useful to predict certain key factors that may be considered for transport planners and decision makers in order to address new regulations or developments regarding this multimodal freight transport and contribute positively in the future success of SSS. Please note that there are a good number of publications that describe a long list of neck bottles of the SSS, such as heavy administration procedures, port terminal infrastructure deficiencies, flexibility and frequency of the SSS service. The purpose of this section is to define the key driving factors of the SSS which can be inferred directly from 
the heuristic model.

The following characteristics are considered to define a reasonable framework of the Short Sea Shipping in the European South Mediterranean region and set a basis of design:

Sea distances ranging from 450 up to 800 nautical miles (nmi);

Fleet size with a gross tonnage ranging from 8,500 GT up to $30,000 \mathrm{GT}$;

SSS multimodal routes that include from $30 \%$ up to $75 \%$ of land freight transport of the total trip distance.

Making several simulations the key factors identified are summarized as follows:

Key Factor 1: The total road distance in the SSS multimodal route should not exceed the $60 \%$ of the total distance to be competitive.

Key Factor 2: According to the area included in the scope of the analyses (South Mediterranean region) port terminal costs and port operation time (vessel loading and unloading) are driving the cost \& time competitiveness of the SSS against the road transport. Investments on port infrastructure and increase the efficiency in the operations may increase the market share of the SSS and promote the modal shift.

Key Factor 3: A carbon emission reduction of up to $40 \%$ (compared to the current situation) can be achieved if the predicted modal shift of the model is obtained. The model (2005 prediction) estimates that a modal shift of up to $20 \%$ of the pure road to the SSS is possible (with regard to the cost \& time criteria defined above) which may lead to a more sustainable transport option. Note that externality costs have not been included in the analyses.

\subsection{Conclusion}

The increasing growth of the transport market demands to the maritime transport an adaptation effort to the redistribution space processes of production centers and consumption and, as a result of it, of the logistic flows and transport. The model presented is just a first step to policy makers or transport planners to demonstrate that Short Sea Shipping is a real alternative to the pure land transport. The tool presented is able to predict the cost and time reductions of the overall freight transport of a region,

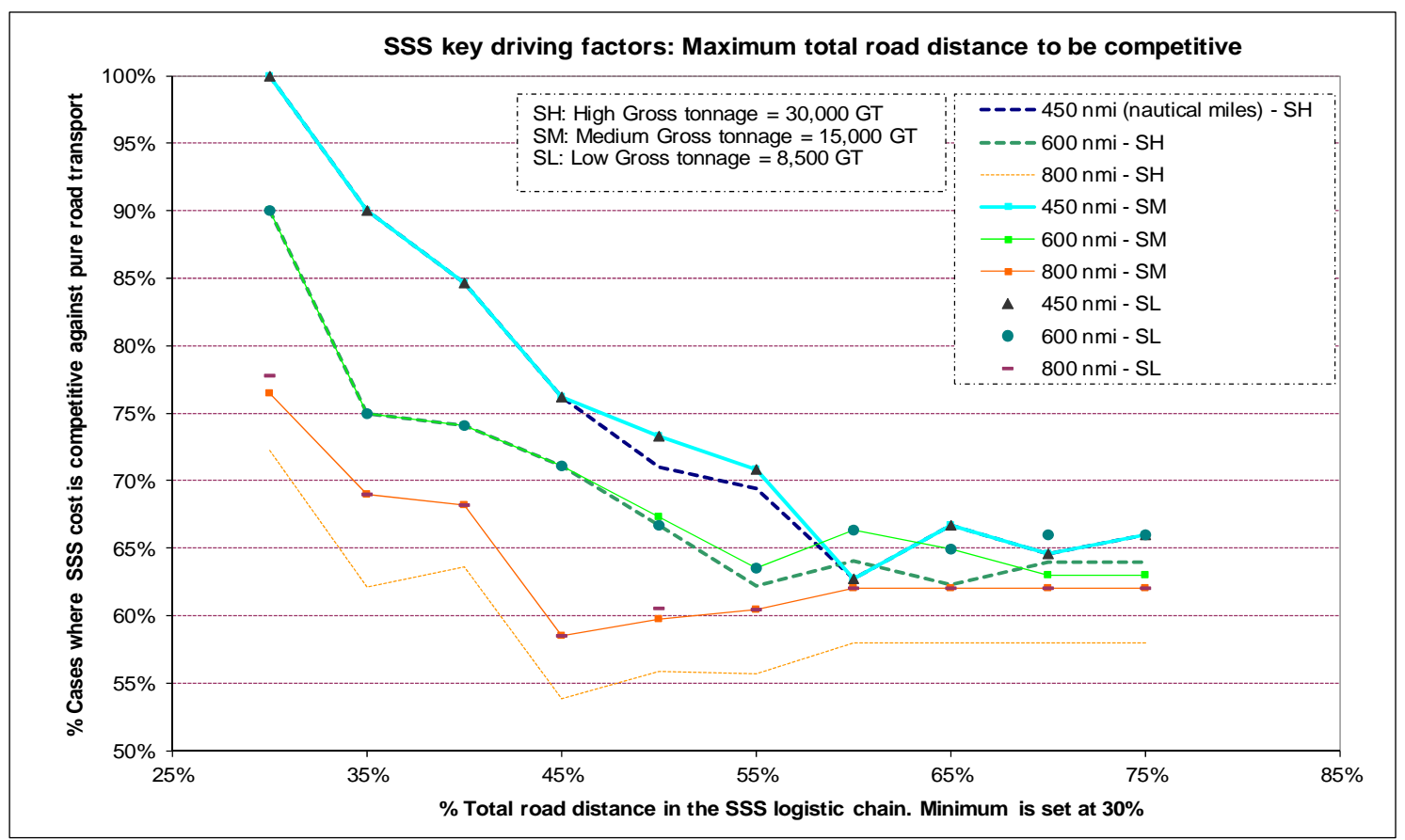

Fig. 2 Freight transport analyses considering different gross tonnage capacities and different sea links in the multimodal SSS option. Source: Own elaboration 

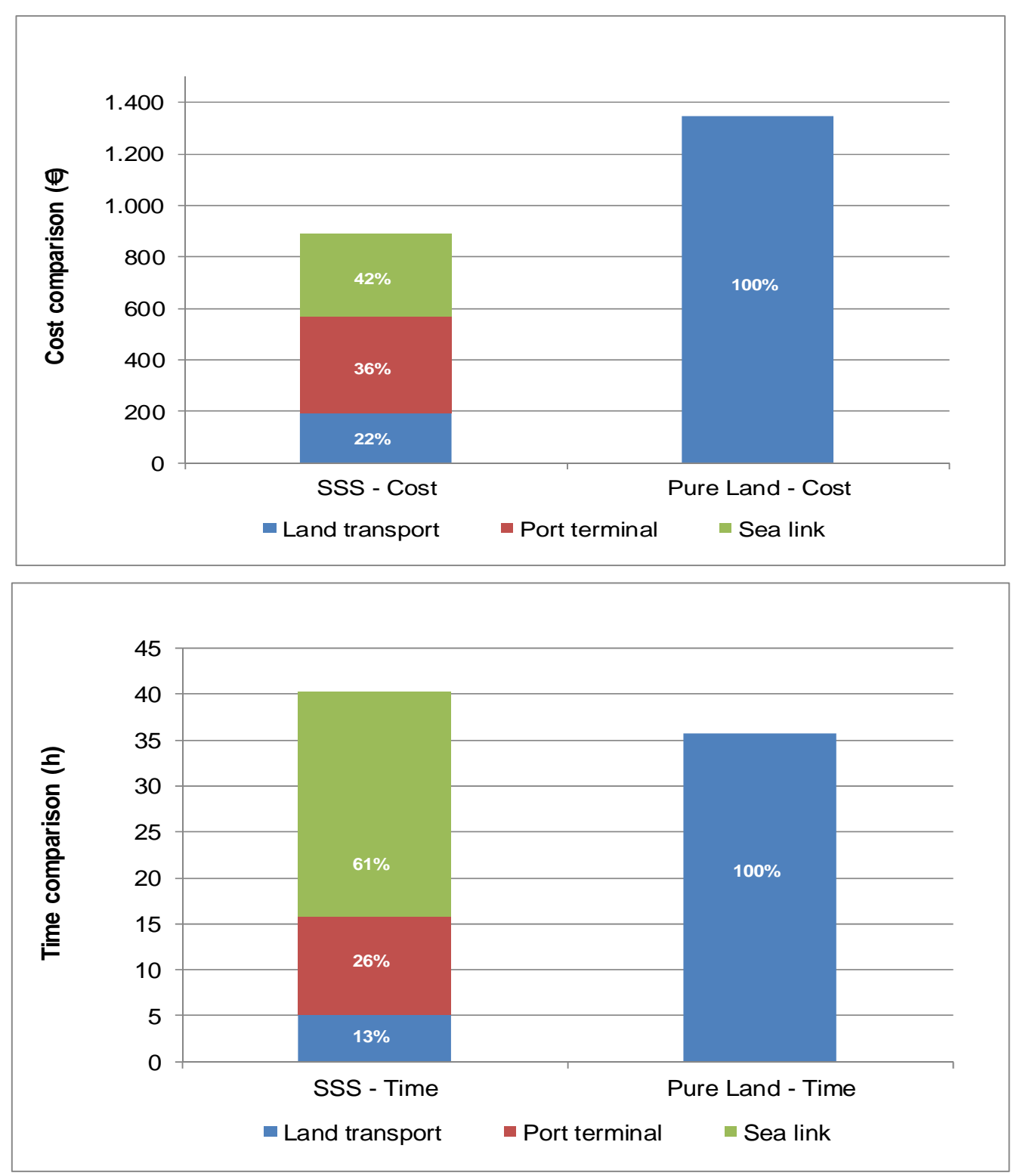

Fig. 3 Cost (up) and time (down) structure of the typical situation where SSS is more competitive than the pure road freight transport. Costs (2005 EUR) are per platform. Source: Own elaboration.

which may be used to plan programs to develop and incent this kind of sustainable freight transport multimodal option.

\section{European Framework of the SSS}

\subsection{EU Initiatives}

The EU vision is to plan a maritime transport space without barriers which extends the Common Market to sea transport. The effective implementation pre-supposes a simplification of administrative procedures and a change in the existing regulatory framework supported by the development of electronic data exchange systems and surveillance capabilities by coastal and authorities in ports.

Two different initiatives have been introduced in the EU to promote the SSS. The first one is the TEN-T, a high level program which includes the improvement of existing maritime links to establish new viable, regular and frequent maritime links for the transport of goods between Member States in order to 
reduce road congestion. The second program is the Marco Polo which aims to shift freight from the roads to more environmentally friendly modes and to support commercially-oriented services in the freight transport market and finance actions involving candidate countries. The characteristics of both programs are briefly summarized below:

In general, the approach to corridors (TEN-T) or through the subvention of services (Marco Polo I and II) have not been fully convincing as they seem to be based more on lobbying than on objective findings. Promoting the greater involvement of PPP (Public Private Partnerships) is the new approach that may overcome the difficulties of the past. Please refer to the European Commission web portal for more details regarding these initiatives. In both cases, a freight demand model like the one presented in this paper should be used for a preliminary estimation of the funds to be assigned to the promotion program.

\subsection{A SSS Reference: Port of Barcelona}

The Port of Barcelona is the leading Port in Spain in Short Sea Shipping (SSS) traffic. The demand for this type of transport has led the Port to set up an increasing number of short-distance maritime lines, which link it to other Mediterranean and North African ports. The competitiveness of Short Sea Shipping and the investment made by port facilities and shipping lines to make this a real alternative to road transport can be clearly seen by the spectacular growth figures. In 2013, the SSS moved a total of 100,716 intermodal transport units (ITU-equivalent to trucks, platforms and trailers) which represents a year-on-year increase of $10 \%$, driven mainly by renewed

Table 2 EU programs to promote the SSS. Source: Own elaboration from Anne Bårseth: Executive Agency for Competitiveness and Innovation (EACI) Marco Polo Unit.

\begin{tabular}{lll}
\hline Program & TEN-T & MARCO POLO \\
\hline Driving force & Public sector driven & Private sector driven \\
Actors & Top-down (Member States) & Bottom-up (undertakings) \\
Schedule & Long-term & Short-term \\
Mission & Creation of transport network & Modal shift objective \\
Target & Infrastructure & Transport services \\
Infrastructure & Strategic infrastructure & Ancillary infrastructure \\
\hline
\end{tabular}

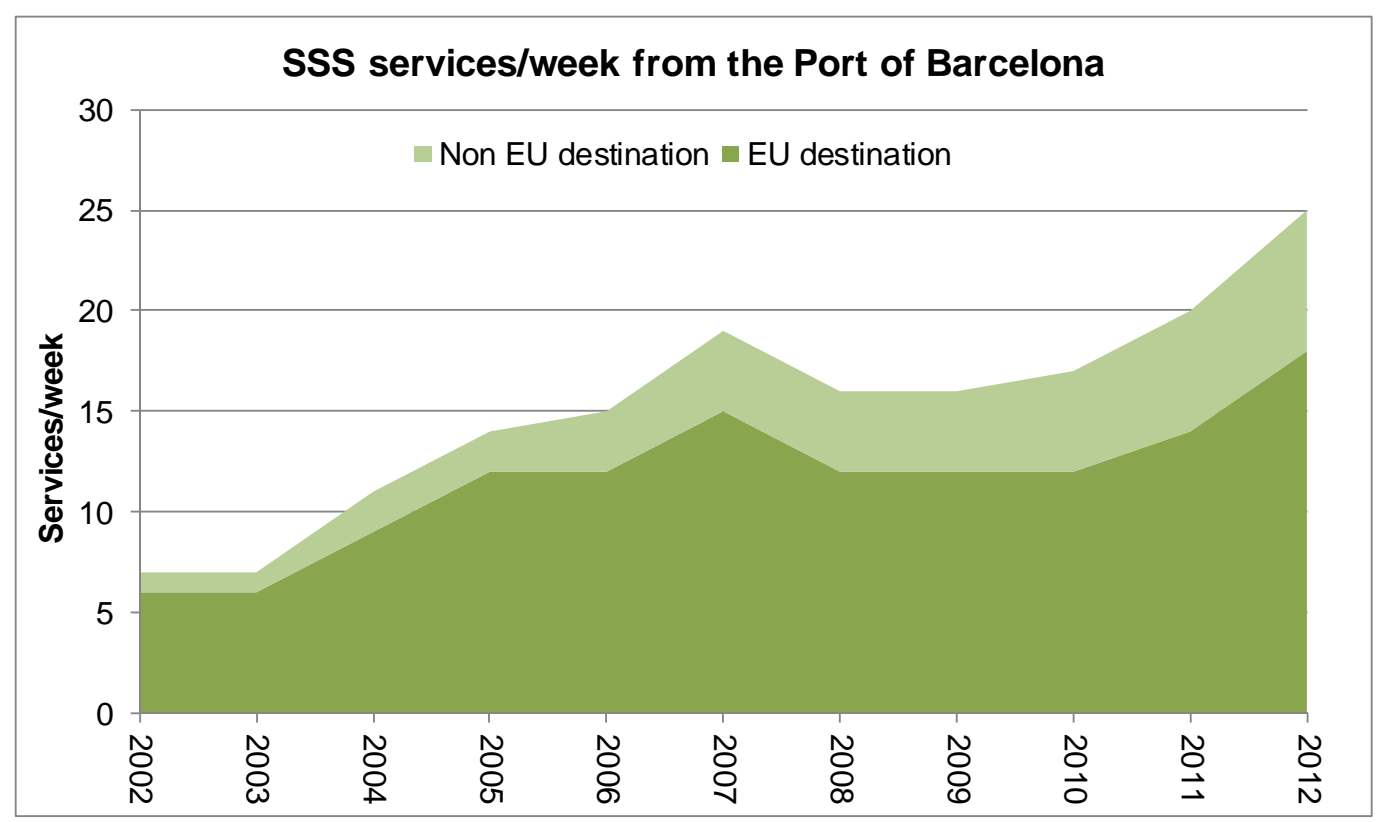

Fig. 4 SSS services per week in the Port of Barcelona. Source: Own elaboration from Port of Barcelona - 2014 data. 


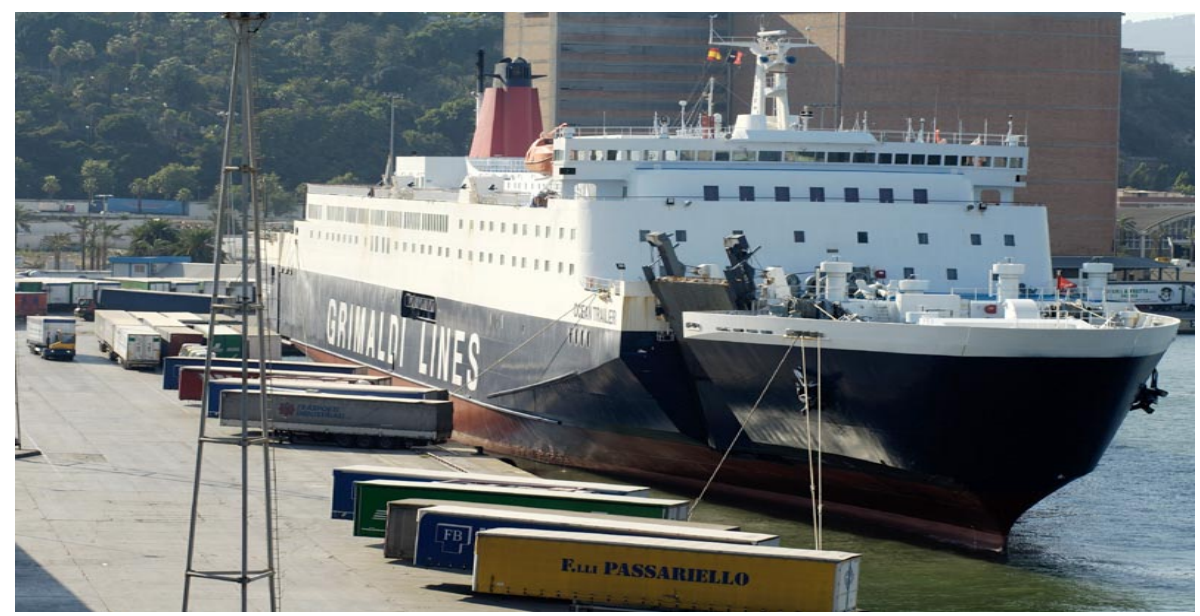

Fig. 5 Grimaldi SSS Terminal in the Port of Barcelona. Source: Port de Barcelona, 2014.

growth in traffic with Italy and a high export capacity of the hinterland.

Thanks to its strategic location and its ever-larger and important hinterland, the Port of Barcelona is developing strategies to increase the number of SSS services and offer a more flexible and competitive maritime transport service to its companies and clients. The Port currently has berthing, loading and unloading areas dedicated to this particular mode of transport and has become a touchstone for this type of short distance traffic.

The Port has three specialized terminals for trucks, vehicles and passengers and frequent SSS services between Barcelona and the main ports of the Mediterranean and North Africa (refer to Fig. 4). The last SSS terminal in the Port of Barcelona (refer to Fig. 5) received a TEN-T contribution of 1.4 million euros (10\% of total project works cost) under the key objective of the improvement of intermodal transport, as it will allow upgrading the efficiency along the whole logistics chain between the Iberian Peninsula, North Africa and Italy through the removal of existing bottlenecks.

\section{References}

[1] Ametller, Xavierand Saurí, Sergi 2007. “Optimización del transporte de mercancías mediante el transporte marítimo de corta distancia.” Universitat Politécnica de Catalunya. Barcelona. Accessed at Aug 10th, 2014. http://upcommons.upc.edu/pfc/bitstream/2099.1/4942/1/ Mem\%C3\%B2ria.pdf

[2] Autoritat Portuària de Barcelona 2014. Accessed at Aug 10th, 2014. http://www.portdebarcelona.cat/

[3] Camarero, Alberto, and Polo, Gerardo. 2005. "Ro-Ro Ships for Short Sea Shipping.” PIANC Magazine (188): 35-41.

[4] Cullinane, K., and Khanna, M. 1998. "Economies of Scale in Large Container Ships.” Journal of Transport Economics and Policy (33): 185-208.

[5] Jansson, J. O., and Sheneerson, D. 1988. "A Model of Scheduled Liner Freight Services: Balancing Inventory Cost against Shipowners' Costs." The Logistics and Transportation Review (21): 3.

[6] Martínez de Osés, F. Xavier and Castells Sanabra, Marcel-la 2005. "Análisis de los buques dedicados al transporte marítimo de corta distancia internacional en España.” Grupo de investigación TRANSMAR. Departamento de Ciencias e Ingeniería Náuticas-UPC. Spain.

[7] Ministerio de Fomento de España 2002. “Informe sobre el cabotaje comunitario o transporte marítimo de corta distancia.” Documento para el consejo informal de ministros de transportes de la Unión Europea. Gijón.

[8] Robusté, F. 2005. Logística del transporte. Barcelona UPC. 